\title{
COVID-19 and Comparative Health Policy Learning; the Experience of 10 Countries
}

\author{
Azam Raoofi, MSc, PhD Candidate'; Amirhossein Takian, MD, MPH, PhD, FHEA ${ }^{1,2,3^{*}}$; Hajar Haghighi, MSc, PhD Candidate ${ }^{1}$; Afsaneh \\ Rajizadeh, MSc'; Zeinab Rezaei, PhD ${ }^{5}$; Samera Radmerikhi, MSc ${ }^{6}$; Alireza Olyaeemanesh, MD, PhD ${ }^{3,7}$; Ali Akbari Sari, MD, PhD ${ }^{1,8}$ \\ 'Department of Health Management, Policy \& Economics, School of Public Health, Tehran University of Medical Sciences, Tehran, Iran \\ ${ }^{2}$ Department of Global Health \& Public Policy, School of Public Health, Tehran University of Medical Sciences, Tehran, Iran \\ ${ }^{3}$ Health Equity Research Center, Tehran University of Medical Sciences, Tehran, Iran \\ ${ }^{4}$ Health Services Management Research Center, Institute for Futures Studies in Health, Kerman University of Medical Sciences, Kerman, Iran \\ ${ }^{5}$ Department of Food Hygiene and Aquaculture, Faculty of Veterinary Medicine, Ferdowsi University of Mashhad, Mashhad, Iran \\ ${ }^{6}$ Social Determinants of Health Research Center, Institute for Futures Studies in Health, Kerman University of Medical Sciences, Kerman, Iran \\ ${ }^{7}$ Department of Health Economics, National Institute of Health Research, Tehran University of Medical Sciences, Tehran, Iran \\ ${ }^{8} \mathrm{Head}$ of the National Institute of Health Research (NIHR), Tehran University of Medical Sciences, Tehran, Iran
}

\begin{abstract}
Background: Since December 2019, the world has been facing one of the most critical health threats of the last decades. In March 2021, the official number of deaths passed 2.6 million worldwide. Most countries have developed policies to control the disease. Nevertheless, countries have experienced different outcomes related to their various adapted policies. Complementing our first report, in this article, we report our findings of comparing the policies adopted to combat coronavirus disease 2019 (COVID-19) in Iran, with those from nine selected countries, including China, Japan, South Korea, Singapore, Germany, the United States, the United Kingdom, Spain, and Italy, to draw evidence-informed policy lessons.

Methods: This is a qualitative study conducted based on document analysis related to COVID-19 policies in Iran and nine selected countries. Using a deductive approach, data were extracted and analyzed based on the components of the WHO Building Blocks Framework. Finally, we compared the Iranian policies with the nine selected countries.

Results: Documents analysis revealed a spectrum of policies, which have led to a variety of outcomes. Based on our findings, three main strategies (widespread testing, comprehensive contact tracing, and timely measures) were the most effective directions to combat COVID-19.

Conclusion: The experience of the first and second waves of COVID-19 showed that the risk of coronavirus is serious and will continue until a vaccine or decisive treatment is achieved. Therefore, countries are required to adopt appropriate and tailored policies to deal with this crisis effectively. Applying the experiences from the previous waves is essential for more efficient performance in the likely upcoming waves.

Keywords: COVID-19, Health policy, Pandemic, Policy making

Cite this article as: Raoofi A, Takian A, Haghighi H, Rajizadeh A, Rezaei Z, Radmerikhi S, et al. COVID-19 and comparative health policy learning; the experience of 10 countries. Arch Iran Med. 2021;24(3):260-272. doi: 10.34172/aim.2021.37.
\end{abstract}

Received: September 8, 2020 Accepted: December 16, 2020, ePublished: March 1, 2021

\section{Introduction}

On the last days of 2019, an unknown type of pneumonia was reported in Wuhan, Hubei province, China, which was later named as coronavirus disease 2019 (COVID-19). ${ }^{1}$ One month later, following an increasing number of cases, on January 30, 2020, the World Health Organization (WHO) announced COVID-19 outbreak as a "Public Health Emergency of International Concern" (PHEIC). ${ }^{2}$ The crisis spread rapidly throughout the world, and on March 11, 2020, the WHO finally declared COVID-19 outbreak a "Global Pandemic". ${ }^{3}$ So far, the pandemic has become the most dangerous threat to health, social welfare, global economy and wellbeing in recent history, ${ }^{4}$ to the extent that the United Nations (UN) Secretary General has cautioned that "the world faces the most challenging crisis since World War II". 5

Ever since the outbreak was announced in China, the WHO has been at the center of global coordination for data analysis, advice provision and assisting countries for preparation in combating the pandemic ${ }^{1}$, including regular reports on the epidemical situation of the disease and the COVID-19 Strategic Preparedness and Response Plan. ${ }^{6}$

Recent epidemics, i.e. severe accurate respiratory syndrome (SARS) of 2003, H1N1 influenza of 2009, and Middle East respiratory syndrome (MERS) of 2012 
were incomparable to the ongoing COVID-19 pandemic in terms of scope, severity, magnitude and dramatic consequences. $^{7}$ As of March 11, 2021, 118754336 individuals in 223 countries have been infected, of whom 2634370 have died. ${ }^{8}$ Coordinated and rapid response by the governments has been known as the key factor during the crisis. ${ }^{8}$ Countries' responses have been diverse in combating COVID-19 (i.e. suppression, isolation, quarantine, lockdown, contact tracing, etc), which have led to a rainbow of outcomes and consequences among various nations, particularly better health outcomes among more resilient health systems, ${ }^{9,10}$ and devastating outcomes among countries that did not respond efficiently. ${ }^{9}$

China, as the origin of the disease, established a central committee led by the prime minister as well as provincial committees commanded by governors. The Chinese's precautionary measures have been based on contact tracing policies in public places, quarantine in contaminated areas and cities, complemented by traffic restrictions for millions of residents. ${ }^{1,11}$ In the United States, the White House Coronavirus Task Force was established on January 29, 2020, whose mandate is coordinating the administration's efforts to monitor, prevent, contain and mitigate the spread of COVID-19. Initially, the federal government chose mitigation strategy and delegated authority and decision-making to the federal, state and local governments to act within the guidelines provided by the Centers of Disease Control and Prevention (CDC) at the federal level. ${ }^{12}$ Similarly, Spain and Italy provided their states with authority to adapt independent different strategies against the crisis, tailored to their contextual needs. ${ }^{9} 13$ By contrast, some Southeast Asian countries such as Singapore, Taiwan and Hong Kong drew upon lessons learned from the experience of SARS epidemic in 2003 , which led to a reduction in the number of positive cases as well as casualties in these countries compared to other high-income nations.?

Following the first two positive cases in Qom city on February 19, 2020, the COVID-19 epidemic was officially declared in Iran. The outbreak spread quickly to adjacent provinces including Tehran, Markazi, Isfahan and Guilan, and by March 5, 2020, all 31 provinces became infected. ${ }^{11}$ Until March 12, 2021, the total number of confirmed cases was 1731558 with 61069 deaths and 1477588 recoveries in Iran. Despite relative success in combating the crisis across most provinces by early May 2020, the country has been facing an increasing return of infected cases, since mid-September. Insofar, the daily new cases rose from 802 on May 2 to 14051 , the highest since the outbreak of coronavirus, on September 28, 2020, during which the number of daily death toll has been reported to be about seven times higher.

Policy learning is crucial in developing timely and appropriate policies and their satisfactory implementation. ${ }^{14}$ COVID-19 has been spreading very quickly worldwide, with many lessons to learn and adopt tailored to each local context. Since the early days of COVID-19 epidemic in Iran, our research team has been conducting an analytical comparative policy analysis of the WHO and selected countries. ${ }^{11}$ Complementing our first report, in this article, we report our findings of comparing the policies and strategies adopted for combating COVID-19 in Iran, with those from nine selected countries. Our findings and policy recommendations will contribute to, we envisage, an ongoing policy learning and exchange of experience to enlighten evidence-based policy making in combating the current epidemic, as well as other upcoming threats in Iran and perhaps similar settings.

\section{Materials and Methods}

This is a qualitative study. We collected a variety of relevant and available articles, documents, programs, reports, websites and official news related to COVID-19 in Iran and nine selected countries and analyzed their content purposefully, based on an adapted WHO framework. In the first step, we reviewed the worldwide prevalence and mortality of COVID-19. Second, we sought the views of four senior experts in the field to select the nine countries to be included in the study. They included five relatively successful countries in dealing with coronavirus (China, Japan, South Korea, Germany and Singapore) and four less successful countries (the United States, the United Kingdom, Spain, and Italy), in addition to Iran. Since the first wave of the virus has been declining in many countries until almost mid-April, and as a result, many stringent policies have been eliminated, in this study, we mainly focused on policies and measures from the beginning of COVID-19 (December 31, 2019) up until April 15, 2020.

We applied a deductive approach for data extraction and analysis. Using categorical content analysis, data were categorized based on the relevant components in our conceptual framework. Experts' opinions were used to select the most appropriate conceptual framework for data analysis. Finally, the Iranian measures and policies were compared with the measures and strategies of the nine selected countries based on the WHO's Six Building Blocks Framework (Figure 1). Introduced in 2007 by the WHO, the framework, is used to categorize strategic goals and operational processes for guiding, creating, restoring, and responding to the health system, and outlines the health system's priorities. ${ }^{15,16}$

\section{Results}

Document analysis of the selected countries shows that they have been adopting different policies and measures in response to the COVID-19 crisis, which has led to different outcomes. Some countries have formulated timely and appropriate measures to deal with the disease, i.e. China, South Korea and Singapore. In contrast, the policies of some other countries, including the United 


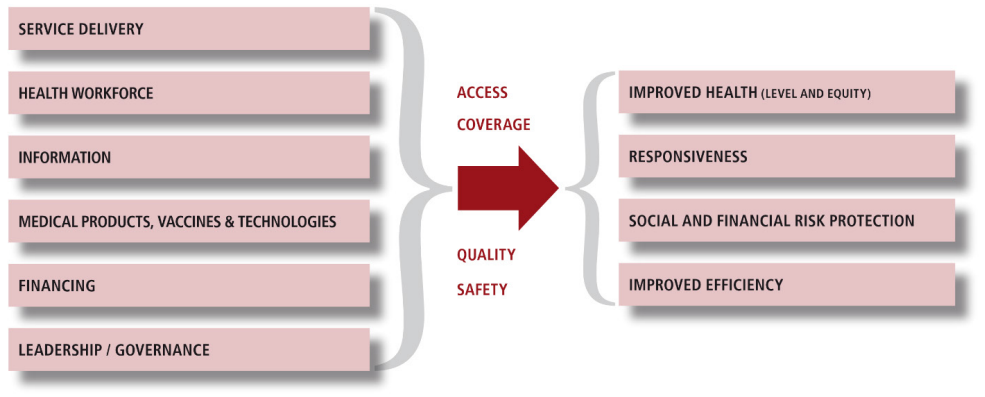

THE SIX BUILDING BLOCKS OF A HEALTH SYSTEM: AIMS AND DESIRABLE ATTRIBUTES

Figure 1. The WHO Health Systems Framework (from Everybody's business--strengthening health systems to improve health outcomes: WHO's framework for action $^{15}$.

States, United Kingdom and Spain, have led to some unfortunate consequences in terms of infection and mortality (Table 1).

Figures 2 to 5, Table 2, and Supplementary file 1 ( Tables S1-S4) present some of the main policy contents of the selected countries, based on six components of the study framework. Figure 6 illustrates the time interval between the first positive cases and the beginning of the basic measures by the ten selected countries.

Overall, the results of the current study revealed that three main strategies including widespread open public testing, comprehensive contact tracing, and timely limitation and mitigation measures, are the most effective directions to combat COVID-19.

\section{Discussion}

The emergence of the novel coronavirus led to rapid spread of COVID-19 around the world and posed significant challenges to almost all countries. ${ }^{20}$ After the epidemic was declared as a PHEIC by the WHO, countries began to implement different measures to break the chain of transmission and control the disease, including active surveillance, early detection, isolation, case management, and contact tracing. ${ }^{21}$ Additionally, the WHO has begun providing non-binding technical guidelines and recommendations ${ }^{22}$ to be adopted by countries partially and depending on their situation. As COVID-19 is continuing to spread worldwide, and countries have been witnessing higher numbers of infected people, comparative policy learning is pivotal to mitigate the risks and facilitate returning to life, although semi or emerging normal life.

\section{Leadership/Governance}

Based on their context and health system infrastructures, governments adopted different strategies to combat COVID-19.' China adopted a three-stage response prevention (to prevent coronavirus transmission from the Hubei province to other areas), treatment (to reduce mortality) and control (to reduce case clusters). The country was divided into four main regions with specified relevant guidelines: non-infected, with scattered cases, with cluster infection and the mass transfer regions. From the outset of the COVID-19 pandemic, China's Central Leadership Group for Epidemic Response was formed under the leadership of the prime minister and the joint prevention committee. Simultaneously, the pandemic control at the provincial level was handed over to the provincial governors. ${ }^{23}$

In Japan, the Prime Minister set-up the Novel Coronavirus Response Headquarter, which is run by a national taskforce led by the Deputy Chief of Staff for Crisis Management and is responsible for decision-making to act against the coronavirus. ${ }^{24}$

In South Korea and Singapore, strong inter-sectoral collaboration was the underlying advantage in combating COVID-19. ${ }^{25,26}$ Thus, in Singapore, the government

Table 1. Comparison of Infected Cases and Deaths Among the Studied Countries Until March 11, 2021

\begin{tabular}{lcccc}
\hline & Total Cases & Total Deaths & Total Cases/1M Population & Total Deaths/1M Population \\
\hline China & 102276 & 4849 & 63 & 3 \\
Japan & 445585 & 8509 & 3520 & 1846 \\
S. Korea & 95176 & 1667 & 90246 & 32 \\
USA & 29000561 & 527068 & 10214 & 5 \\
Singapore & 60080 & 29 & 30479 & 879 \\
Germany & 2558455 & 73301 & 62352 & 1840 \\
UK & 4248290 & 125343 & 68075 & 1545 \\
Spain & 3183704 & 72258 & 52579 & 1682 \\
Italy & 3175807 & 101564 & 20434 & 721 \\
Iran & 1731558 & 61069 & & 5 \\
\hline
\end{tabular}




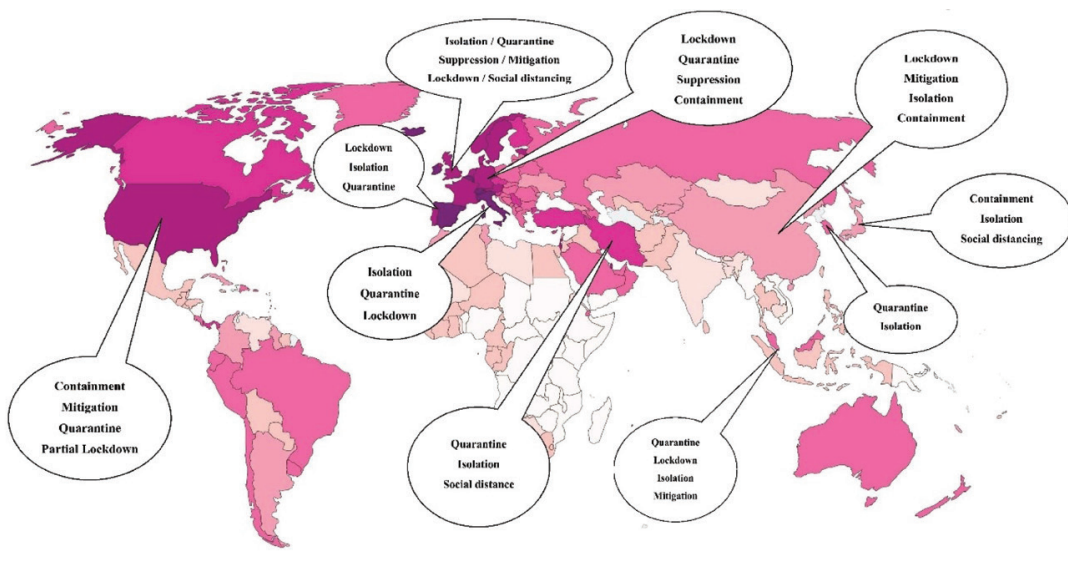

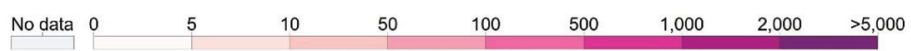

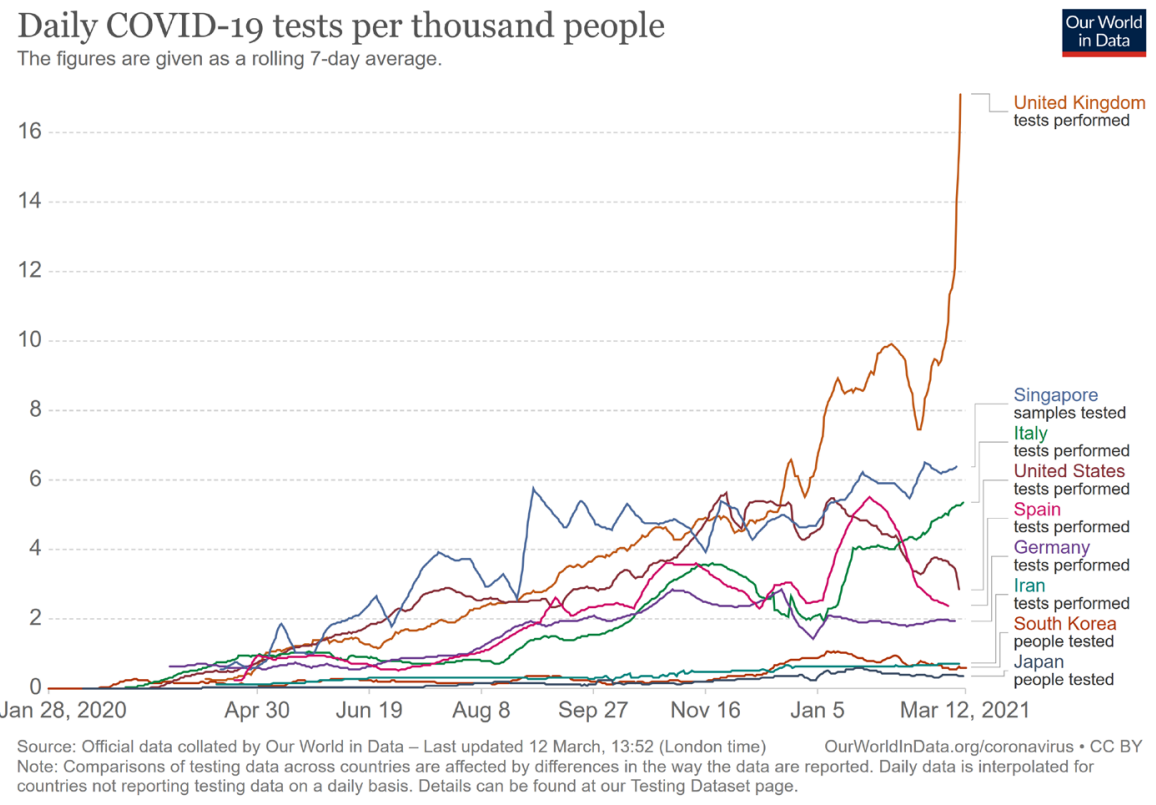

Figure 3. Daily COVID-19 Tests per Thousand People in Selected Countries (From Our World in Data ${ }^{18}$.

established formal platforms for multi-ministry and crossorganizational coordination to set-up a multi-sectoral committee for making decisions during the pandemic. ${ }^{9,26}$

In Italy, the government assigned the task of coordinating the necessary interventions to the head of the Civil Protection Office (CPO). The head of the CPO formed a scientific-technical committee to implement necessary measures to protect the public. ${ }^{27}$

In Germany, the "Crisis Management Team" was formed under the joint chairmanship of the Minister of Interior and the Minister of Health to strengthen the cooperation among federal states more effectively. ${ }^{28}$ Germany pioneered a meaningful inter-sectoral collaboration with other countries under direct political support of the
Chancellor to learn from the experience and support the adoption of COVID-19 policies in the country. ${ }^{29}$ Unlike Germany, in the United States, despite warnings from the Ministry of Health $(\mathrm{MoH})$, the president and government did not take the pandemic seriously at the beginning. Nevertheless, the administration gradually moved to adopt more appropriate policies in line with the CDC decisions. ${ }^{30}$ Following warnings from the $\mathrm{WHO}$ and the CDC, the US government formed Information and Coordination Committee for Data and Statistics related to Coronavirus. ${ }^{31}$

Similarly, in Iran, the COVID-19 National Committee was established under the leadership of the Minister of Health and Medical Education, which was later handed 


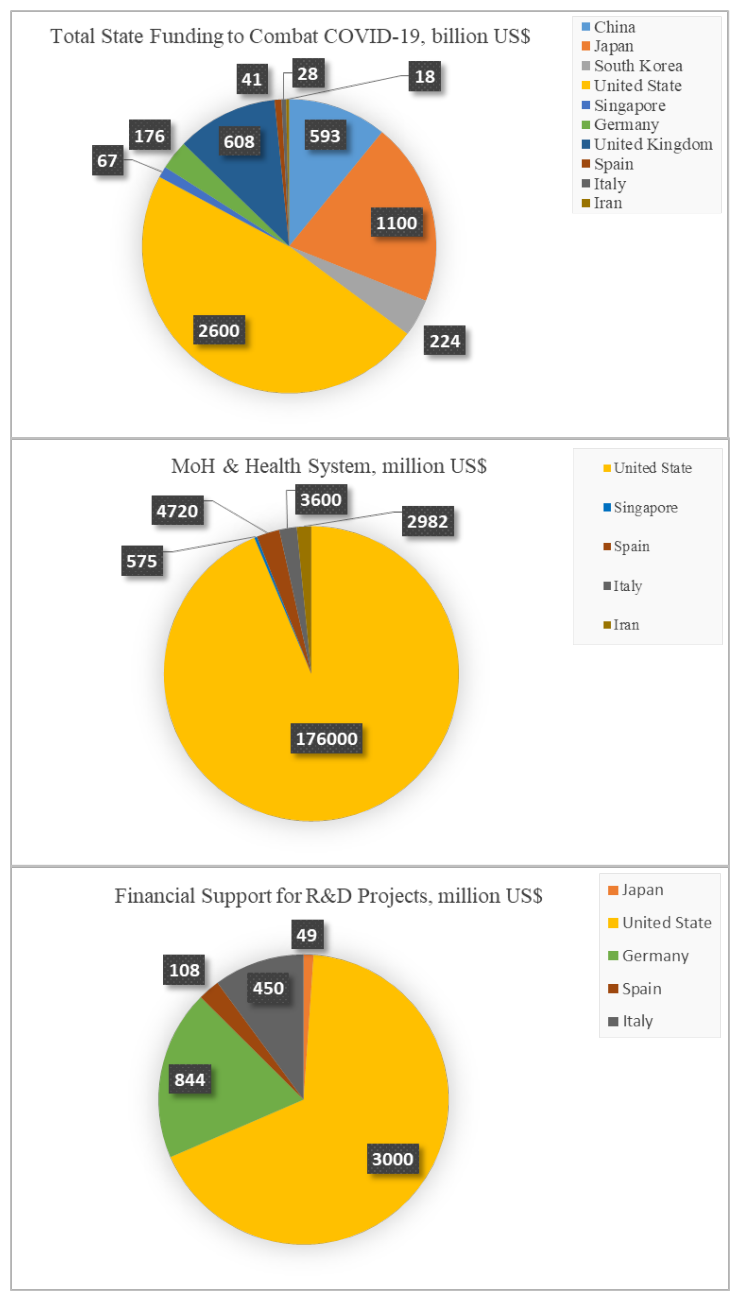

Figure 4. Budgets Allocation to Combat COVID-19 in Selected Countries.

over to the President, and membership of some cabinet ministers, to enhance coordination and consistency and to increase inter-sectoral collaboration. Simultaneous, COVID-19 provincial committees were established under the leadership of the governor. $^{32,33}$

Asian countries including Singapore and South Korea, were relatively more successful in fighting against COVID-19, mainly due to their timely response. ${ }^{?}$

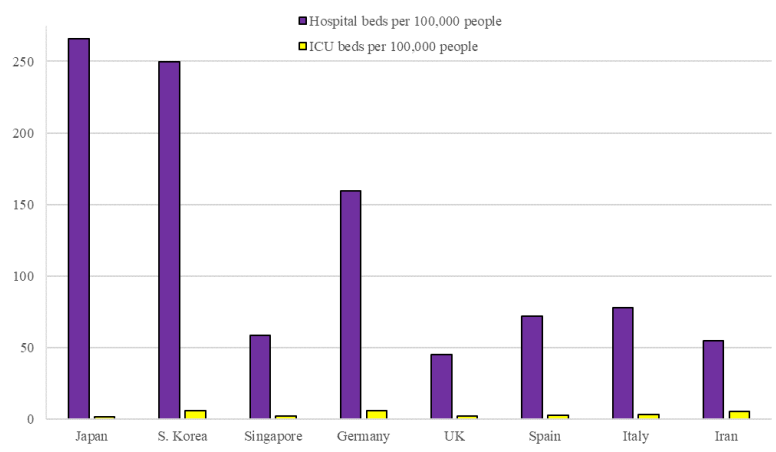

Figure 5. Total Hospital and ICU Beds of the Selected Countries. ${ }^{19}$

Singapore began to screen incoming passengers by measuring their body temperature before reporting the first positive case of COVID-19 outside China. Besides, entry restriction was imposed on those who had traveled to China in the past 14 days. ${ }^{9}$ Another timely measure by Singapore against COVID-19 was the declaration of "stay at home", which has become mandatory for all Singaporeans. ${ }^{1}$ As the number of infected people increased across the country, the Prime Minister also requested for the implementation of "circuit breakers" law for a month. The bill allowed the Minister of Health to close the sites or use them to quarantine and isolate patients. During the passage of the bill, with the aim of tightening regulations about the spread of COVID-19, any form of gathering in public places was prohibited.'

South Korea is another country that was prepared to deal with this pandemic before the start of the COVID-19 outbreak. ${ }^{34}$ Three days after the announcement of the disease in China, the Korean CDC formed an emergency team to investigate the disease. On March 6, South Korea announced a reduction in the number of new cases from a peak of more than 800 daily in late February to two new cases on May 6, 2020. ${ }^{35}$ This was achieved without any lockdowns, roadblocks, and restrictions on movement and assembly. ${ }^{36}$ While many countries took tough measures to stop the virus spread, South Korea presented

Table 2. Selected Policy Contents of the Selected Countries in Relation to Health Workforce

\begin{tabular}{|c|c|c|c|c|c|c|c|}
\hline & \multirow[b]{2}{*}{$\begin{array}{l}\text { Health Workforce } \\
\text { Per } 10000 \\
\text { Population }\end{array}$} & \multicolumn{6}{|c|}{ Workforce Shortage Compensation } \\
\hline & & $\begin{array}{l}\text { Hiring Additional } \\
\text { Health Workers }\end{array}$ & $\begin{array}{c}\text { Re-allocating } \\
\text { Health } \\
\text { Professionals }\end{array}$ & $\begin{array}{l}\text { Returning Retired } \\
\text { Health Professionals }\end{array}$ & $\begin{array}{l}\text { Freelance Contracts } \\
\text { for Unregistered Staff } \\
\text { (Temporary Practice) }\end{array}$ & $\begin{array}{l}\text { Foreign Health } \\
\text { Workers }\end{array}$ & $\begin{array}{c}\text { Deployment } \\
\text { of Last Year } \\
\text { Students }\end{array}$ \\
\hline China & No data & $\sqrt{ }$ & \multicolumn{5}{|c|}{ Sending health experts from all over China to Hubei } \\
\hline Japan & 860 & \multicolumn{6}{|c|}{ No data } \\
\hline S. Korea & 406 & & & & \multirow{2}{*}{$\begin{array}{l}\sqrt{ } \\
\sqrt{ }\end{array}$} & $\sqrt{ }$ & $\sqrt{ }$ \\
\hline USA & 682 & $\sqrt{ }$ & $\sqrt{ }$ & $\sqrt{ }$ & & & $\sqrt{ }$ \\
\hline Singapore & 252 & \multicolumn{6}{|c|}{ No data } \\
\hline Germany & 669 & & & \multirow{3}{*}{$\begin{array}{l}\sqrt{ } \\
\sqrt{ } \\
\sqrt{ }\end{array}$} & \multirow{3}{*}{$\begin{array}{l}\sqrt{ } \\
\sqrt{ } \\
\sqrt{ }\end{array}$} & $\sqrt{ }$ & \multirow{2}{*}{$\begin{array}{l}\sqrt{ } \\
\sqrt{ }\end{array}$} \\
\hline UK & 664 & $\sqrt{ }$ & $\sqrt{ }$ & & & & \\
\hline Spain & 356 & & $\sqrt{ }$ & & & & \\
\hline Italy & 319 & $\sqrt{ }$ & $\sqrt{ }$ & $\sqrt{ }$ & $\sqrt{ }$ & $\sqrt{ }$ & $\sqrt{ }$ \\
\hline Iran & 99 & $\sqrt{ }$ & $\sqrt{ }$ & $\sqrt{ }$ & $\sqrt{ }$ & & $\sqrt{ }$ \\
\hline
\end{tabular}




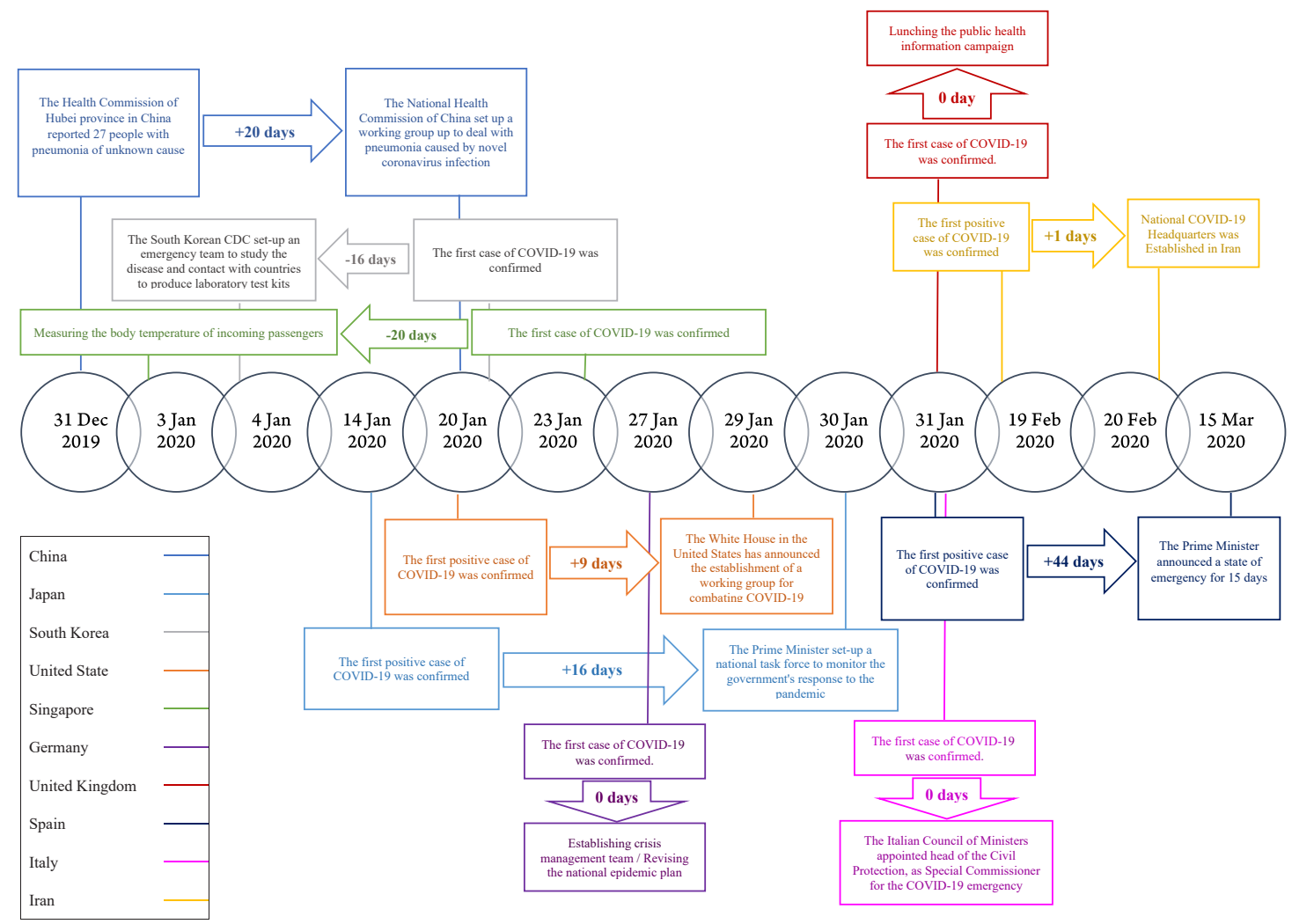

Figure 6. Time Interval between the First Confirmed Cases and the First Basic Measures in Each Country.

another strategy to control the disease, so-called TRUST: transparency, strong screening, quarantine, unique but universally applicable testing and accurate control and treatment. ${ }^{34,35,37}$ Furthermore, under the new rules, all passengers arriving in South Korea were required to install a smart app on their mobile phones to be able for checking their signs regularly. ${ }^{38}$ Also, all people suspected of having coronavirus who did not cooperate with the diagnostic test were prosecuted. ${ }^{39}$

China implemented policies for early detection, early isolation, early diagnosis and treatment of identified patients, all of which were highlighted by the WHO as contributing factors to China's relatively effective response to the pandemic. ${ }^{23,40}$ Body temperature check was executed at the borders as well as entrances of all institutions and hospitals. ${ }^{41}$

Similar to Asian countries, Germany also quickly responded to the pandemic through simultaneous implementation of three main strategies: containment (tightening the country's borders, prohibition of entry travelers from Iran, Italy, South Korea and China, testing incoming travelers since the declaration of first positive cases in Europe, and imposing 14-days quarantine for the cases); protection (with the aim of protecting vulnerable people) and mitigation (mandatory schools closure, most jobs and any gatherings in community, and observing social distance between individuals) to combat the spread of COVID-19. ${ }^{42}$ Moreover, individuals who were in contact with patients were classified into three separate categories with separate measures to break the infection chain. ${ }^{42}$

In contrast, some European countries such as Italy, Spain, and the United Kingdom, as well as the United States have relatively delayed the implementation of timely measures to combat COVID-19. ${ }^{27}$ Consequently, the health system faced a massive burden of infected cases that resulted in unprecedented COVID-19 casualties.' Following the increase in the number of infected cases and reaching 627 death during 24 hours in Italy, the Prime Minister announced a lockdown for the entire Italy encompassing all 60 million citizens, ${ }^{43}$ with the army and police responsible to implement strict military quarantine. ${ }^{44}$ Similar to Italy, delays in declaring a state of emergency in Spain caused people to travel, resulting in rapid spread of the virus throughout the country. The central government announced a general lockdown 45 days after the first positive case in Spain for 15 days, which was extended again. As a result, all flights were canceled, residents were obligated not to leave their homes except in emergencies and workers were allowed to take leave. ${ }^{1}$ Similarly, in the United Kingdom, the Prime Minister initially resisted quarantine and lockdown due to the concern of "real and unnecessary economic damage". Public Health England, in accordance with the Dangerous Pathogens Advisory Committee, did not classify COVID-19 as "Highly Effective Infectious Disease" at the beginning, which led 
to virus control programs beginning with delay in the United Kingdom. ${ }^{45,46}$

In Iran, quarantine measures and traffic restrictions were not initially applied and people were only encouraged to stay at home. Some interventions were also taken by the government to facilitate the staying at home strategy and implement the social distance policy, including the closure of schools, universities, jobs, religious places and ceremonies, banning cash transfer in banks, extension of third-party insurance expiration date, etc. Despite all interventions, the government's initial delay in implementing prevention and mitigation measures had a great impact on the widespread prevalence of the disease, which led to contamination of all 31 provinces within two weeks. Consequently, following an increase in the prevalence of COVID-19 due to New Year holiday, the national committee urged the government to impose stricter traffic restrictions. To ensure public compliance, police and Basij Organization (a militia group affiliated with the Army) were settled in inter-provincial borders to impose traffic restriction. ${ }^{11}$ Since April 11, 2020, smart social distancing policy has been implemented to reopen the businesses and reduce the restrictions gradually. According to this policy, medium and low-risk businesses resumed their activities with strict adherence to health protocols, whereas high-risk business activities will stay closed until further notice. ${ }^{47}$ The Ministry of Health and Medical Education (MoHME) also requested all trade and industrial units to register in order to receive guidelines and environmental health requirements for their employees and customers depending on the nature of their activities. ${ }^{48}$

\section{Service Delivery}

In China, when the disease was identified, all hospital beds in affected areas were allocated to controlling the disease, while fever clinics were established throughout the country for early screening. ${ }^{23}$ Similarly, in Singapore, the $\mathrm{MoH}$ activated a network of more than 800 public health clinics to improve the management of COVID-19 in the primary care units. ${ }^{49}$ Iran also equipped and prepared its hospitals as well as comprehensive primary healthcare (PHC) centers to do the same. However, the insufficient coordination between primary and secondary care, plus inadequate communication with the public led many people to directly go to hospitals instead of being screened in the PHC centers. ${ }^{11}$

Another criticism is Iran's failure to utilize the capacity of the private sector to reduce the heavy burden of COVID-19 crisis on the public sector. This was in contrast to the United Kingdom where the UK's National Health Service (NHS) entered into negotiations with the private sector to respond to the epidemic. The UK's NHS also freed 30000 beds by discharging patients with relatively stable conditions and enhanced its emergency construction work to add to the capacity of existing hospitals. Additionally, the UK's NHS converted two Conference Centers in England and Scotland into temporary hospitals, which was also extended to other important UK conference centers. ${ }^{50}$

In Spain, although the capacity of hospital beds tripled, $80 \%$ of ICU beds were still occupied by COVID-19 patients. ${ }^{1}$ Italy was among the top ten countries in Europe in terms of the number of ICU beds per 100000 population (12.5). Also, due to the cancellation of non-emergency surgeries, operating room beds in Italy are dedicated to intensive care. Moreover, the Italian government, with the help of the army, has built temporary hospitals with minimal resources for patients with COVID-19.51 The Singapore $\mathrm{MoH}$ also announced that all COVID-19 treated patients who have been discharged from hospitals should be transferred to the recovery hospitals. ${ }^{52}$ In Iran, hotels were used to accommodate recovering patients. Also, the largest shopping center in Tehran and the Tehran Exhibition Center were converted into 3000 and 2000bed mobile hospitals, respectively. ${ }^{11}$

Following the emergence of the novel coronavirus in China, the Korean CDC began to cooperate with manufacturers to develop its commercial diagnostic test kits. ${ }^{53}$ As of April 8, 2020, 638 public health centers and medical institutions, including drive-thru and walkthru stations, were conducting screening. South Korea has increased its daily testing capacity from 3000 tests per day in February to nearly 20000 tests per day as of April, reaching more than two million tests by October 2, 2020, one in every 22 people. ${ }^{54}$ Similar to South Korea, the Singapore's $\mathrm{MoH}$ also rapidly increased the laboratory capacity of the reverse transcriptase-PCR (RT-PCR) test to 2200 tests per day for a population of 5.7 million. ${ }^{49}$ To identify infected cases at the first level, Singapore tested all cases of pneumonia, patients admitted to Intensive care units (ICUs), patients with influenza and people with infectious problems. ${ }^{9}$ In Germany, the widespread coverage of COVID-19 testing for all people, and the presence of laboratory kits in all medical diagnostic laboratories have led to the identification of carriers. Evidence-informed policy making and strong management, in addition to the higher percentage of affected young people who had a lower mortality rate due to their better physical condition than the elderly, were the reasons for lower mortality in Germany. ${ }^{55}$ Furthermore, the invention of a new diagnostic test that detects novel coronavirus 2.5 hours after the exposure was another effective measure in early detection of carriers and breaking the transmission chain. ${ }^{28,56}$

The United Kingdom also developed a new diagnostic test, which was available to 12 laboratories in the United Kingdom, allowing them to test 1000 people a day. The testing capacity increased to 10000 tests per day on March $28 .{ }^{57-59}$ In Iran, due to limited facilities and inadequate laboratory kits, COVID-19 RT-PCR was initially only performed at the Department of Virology at the School 
of Public Health — Tehran University of Medical Sciences and the Pasteur Institute of Iran. Iran's laboratory capacity has gradually increased, so as of July 22, 190 laboratories across all 31 provinces are able to perform more than 25000 COVID-19 RT-PCR tests. ${ }^{60}$

In terms of treatment strategy, South Korea adapted a differentiated treatment approach, based on which patients were classified and treated based on their risk. Patients at higher risk were hospitalized. In contrast, low-risk patients were sent to dormitories provided and equipped by the private sector. The type of treatment also varied, from complete isolation in negative pressure chambers to antiviral and antibiotic compounds to simple monitoring. ${ }^{39,61}$ In a similar measure, the Italian $\mathrm{MoH}$ has been advising asymptomatic patients and people with mild symptoms to refrain from visiting hospitals and to remain in home isolation until the test will become definitively negative. ${ }^{51}$

\section{Financing}

The Chinese government allocated 9.95 billion RMB (about $\$ 1.41$ billion) for public services, epidemic prevention and control to provide better healthcare services and prevent transmission. ${ }^{23} \mathrm{New}$ health insurance policies were also introduced regarding "health insurance payments and compensation", based on which 65\% of the medical expenses of COVID-19 patients were paid by insurance companies and the remaining 35\% were paid by the government. The South Korean government also took specific measures to ensure people's well-being in emergencies, such as passing special laws to cover the costs related to COVID-19. The government used emergency financial resources to provide free hospitalization for the poor and allocated additional funding to combat COVID-19. ${ }^{62}$ In the US, the Congress passed the largest COVID-19 package to date under the Coronavirus Aid, Relief, and Economic Security Act (CARES Act), along with three other pieces of emergency legislation, accounting for approximately $\$ 2.6$ trillion, of which, about $\$ 176$ billion was allocated to hospitals and health care providers. ${ }^{63}$ In Singapore, the $\mathrm{MoH}$ has pledged to pay all bills for suspected or infected patients. ${ }^{49}$ Similarly, insurance companies were responsible for paying the expenses of COVID-19 patients in Germany. To compensate hospitals and doctors, a law was passed to prevent treatment disruption, additional budget was allocated to help people during quarantine. ${ }^{28}$ With the declaration of emergency conditions, the Italian government initially allocated extra $€ 5000000$ (about \$6 million) to implement the first interventions. ${ }^{27}$ Moreover, the government has opened a special account for COVID-19 to maintain transparency and accountability, build public confidence and prevent any possible fraud. It has also incentivized healthcare providers through allocation of additional payments. ${ }^{64}$ In the United Kingdom, the issuance of the premium payment law was approved by the government.

In Iran, the Planning and Budget Organization allocated about $\$ 3.125$ billion to the health system, plus one billion Euros (about \$1 174225000) from the National Development Fund to combat COVID-19. ${ }^{65}$ All people with symptoms or in contact with a symptomatic or positive COVID-19 test were also entitled to free-ofcharge RT-PCR tests. Further, the government allocated funds and tax breaks for the production of masks and disinfectants. ${ }^{66}$

\section{Health Workforce}

Human resource management was one of China's key measures to provide health workforce in each city based on their needs. Thousands of healthcare workers from all over China were transferred to the hospitals in the Hubei province, especially in Wuhan. ${ }^{23}$ In Germany, in addition to new manpower recruitment in the health sector, medical students were encouraged to join the medical staff in hospitals. ${ }^{28}$ The NHS in the United Kingdom increased its health care personnel, removed the barriers to recruit retired NHS employees and social workers and employ medical and nursing students temporarily. ${ }^{46,50}$ In Spain, non-specialist medical graduates, retired healthcare workers, and final year medical and nursing students were recruited, while the contracts of medical residents were renewed. ${ }^{13}$ In Italy, many anesthesiologists who previously served in the operating room were transferred to managing intensive care and emergency medical care allocated to the patients with COVID-19. ${ }^{51}$ In Iran, similar to other countries, retired workforces and final year nursing students were called in to help, while newly-graduated nurses who were admitted in the employment exam, promptly entered the field by eliminating administrative bureaucracy. ${ }^{11,61}$

\section{Information}

In China, mass media and video conferencing were used for public health education, i.e. mask wearing, with the assistance of outstanding individuals and national figures. These trainings were offered to all age groups and even preschool children. ${ }^{23}$ Public health education in Germany began from the first stages of the virus spread. To reach out to minorities, refugees and non-German speakers, the guidelines were also translated to six different languages and posted on the $\mathrm{MoH}$ website. ${ }^{28}$ Healthcare workers dealing with COVID-19 received extra training in terms of diagnoses, medical care, infection control, and the use of personal protective equipment (PPE) ${ }^{28}$ Empowering the public through the national media, establishing public health information campaigns, encouraging people to stay home and installing banners and announcements in the subways were among the measures taken by the United Kingdom. ${ }^{46,67}$ Mass media in Spain and Italy also played significant roles in providing precise information for public 
health education. ${ }^{13,51}$ Furthermore, the $\mathrm{MoH}$ in Italy introduced a public website and a direct hotline (1500) to provide people with access to the latest information about the pandemic. ${ }^{68}$ In Iran, in terms of public education, the MoHME, in collaboration with Medical Universities provided educational information through social media, national TV and educational billboards in the streets. Furthermore, religious clerics were trained and asked to encourage people to adhere to health protocols during the holy month of Ramadan. ${ }^{11}$ The MoHME also prepared a number of national guidelines for many careers, public places, and even special groups such as chronic patients, pregnant women, people with chronic conditions, and the elderly to raise public awareness. ${ }^{61}$ The MoHME also launched an official website of COVID-19 epidemiology that provides up-to-date statistics, reports, guidelines and information for various groups of the society. ${ }^{69}$

With the widespread use of big data and information technology, China has developed an intelligent system for controlling the disease. In Wuhan, more than 1,800 teams tracked tens of thousands of people in contact with the infected patients, ${ }^{40}$ and were ordered to stay in quarantine for 14 days if suspicious. ${ }^{23}$ Two mobile applications have helped in enforcing the restrictions by providing offline services, and more importantly, tracking people's movements and even warning individuals to avoid unnecessary exits from home. Besides, everyone had a type of traffic light system with color codes on their mobile screen, in which green, yellow, or red designated the person's health status. ${ }^{40}$

Perhaps, the most extensive and organized strategies of patients' contact tracing was performed in South Korea. These include the use of new technologies to monitor patients through closed-circuit television cameras, tracking bank cards, and the use of mobile software to identify suspicious individuals in the early stages. Health officials track patients' movements using security camera footage, credit card records, Global Positioning System (GPS) data from their cars, and data from software installed on mobile phones. The government also used a GPS tracking program to share and publicize patients' movements. ${ }^{35}$ Furthermore, patients' withdrawal from quarantine (for those under house quarantine) was monitored by software installed on their mobile phone and fined up to $\$ 2500$ in case of violation. ${ }^{70}$ Furthermore, the government invited companies to develop programs that visualize patients' anonymous graphical data and made it available to the public. $^{71}$

The Singaporean government also performed active follow-up of contacts to break the transmission chain. The Government Technology Agency designed the first telephone software for smartphones to track all contacts, ${ }^{9}$ which led to the diagnosis of about $53 \%$ of patients through contact tracing. ${ }^{72}$ People who came in contact with a patient or suspicious person were called three times a day if the contact was close, and once a day if the contact was not close, so that their fever and respiratory symptoms could be checked. People would be taken to hospitals if they had symptoms after the contact. Close contacts with the COVID-19 patient underwent 14-day compulsory quarantine, and contacts with lower risk were actively monitored. ${ }^{49,72}$ In Germany, two applications were used to track and manage contacts and identify contaminated sites in the country. ${ }^{28}$ In Iran, during the first stages of COVID-19 spread, contact tracing was not followed-up actively. Iran introduced an application, called "Mask", to identify the designated infected areas, as well as to allow individuals to assess the likelihood of being infected by regularly answering the application questions. ${ }^{61}$ Moreover, if people are exposed to infected individuals, they would be warned by this application. Nevertheless, using this application was not mandatory and it was not widely advertised; therefore, a large percentage of the population have no information about this application and how to use it. Worse still, the application has been removed from the Google Play page due to US unilateral sanctions against Iran, which even makes it harder to access.

\section{Medical Products, Vaccines and Technologies}

China initially pioneered the development and use of COVID-19 diagnostic kits. Currently, there are at least six local RT-PCR test kit manufacturers approved by the National Medical Products Administration. In general, manufacturers have the capacity to produce and distribute up to 165000 tests per week. ${ }^{23,73}$ South Korea has also a large-capacity healthcare system and a sophisticated biotech industry to produce test kits. ${ }^{25,36}$ Although Iran initially suffered from a shortage of diagnostic kits, which was partially exacerbated by the US unilateral sanctions, ${ }^{74}$ it has become self-sufficient in terms of producing diagnostic kits. ${ }^{75}$ As of November 17, 2020, there were nine knowledge-based companies in Iran that produce an average of more than 8 million RT-PCR diagnostic kits per month. ${ }^{76}$

The Chinese government focused on supply and price control of medical products, i.e. masks and other PPEs to increase people's access to these equipment. Moreover, some Chinese major corporations donated free healthcare protective facilities to healthcare centers. ${ }^{23}$ In Germany, the government has authorized pharmacies to produce and sell alcohol-based homemade disinfectant solutions, while the European Union was asked for help in providing medicine. ${ }^{28}$ There is conflicting information about Britain in the provision of medical and protective equipment. A number of sources have stated that the government has been able to take effective measures to provide and distribute protective equipment, but there are also reports of complaints from the medical team and healthcare workers for not receiving adequate protective equipment, so medical staff have had to purchase PPEs out of their 
pocket. ${ }^{46}$ A team of health workers were also dispatched from China to Italy with a consignment of medical equipment, followed by imports from South Africa. ${ }^{51}$ Iran has also increased access to the healthcare equipment, including masks, through enforcing laws to ban the export and sale of masks to unauthorized individuals and legal entities, to issue import licenses for a variety of masks with minimal tariffs, and rationing and distributing medical masks in medical centers. ${ }^{11}$ Besides, in the early days of crisis, the Iranian government distributed free health packages, including masks, disinfectant gels along with educational content with the aim of improving the public awareness in the city of Qom. ${ }^{11}$ On April 19, Iran announced that domestic mask production has increased from 150000 to three million per day. ${ }^{77}$

In China, non-COVID-19 healthcare services were provided through online technology and telemedicine (smartphones or personal computers). ${ }^{78}$ In Italy, also, to prevent the spread of the virus, telemedicine technologies have replaced direct referral of people for medical advice. ${ }^{51}$ Similarly, In Iran, the MoHME launched the 4030 call center with 2000 special phone lines, plus the use of SIB (Integrated Health Portal of Iranians) for screening purposes and providing the necessary advice about individuals' health conditions. ${ }^{11}$ Besides, the 1666 call center with 120 hotlines has been allocated by the Health Insurance Organization of Iran for this purpose. Nevertheless, telemedicine and e-health programs have not been widely used in Iran towards acceleration of the process of service provision, early detection, and outbreak prevention of COVID-19. ${ }^{11}$

In the field of research, the Chinese government launched a series of emergency research programs on virus genomes and vaccine development. ${ }^{23}$ Until now, many countries including Germany, United Kingdom, Iran and the United States also allocated specific budget for vaccine development as the main expected strategy to fight COVID-19. ${ }^{11,28,42,79,80}$ As of December 31, 2020, WHO validated the first COVID-19 vaccine for emergency use, which was reported to be over $90 \%$ effective. Of other COVID-19 candidate vaccines, 181 were in the preclinical evaluation and 69 were in the clinical evaluation, 16 of which have reached phase III of the clinical trial by February 16, 2021. The trials have been supported by various manufacturers in the United Kingdom, China, Russia, the United States, Germany, etc. ${ }^{81}$

GAVI, the Vaccine Alliance also launched a global initiative, called COVAX, to pool resources and share vaccine development risk, with the aim of working with vaccine manufacturers to provide countries with equitable, safe, and effective access to the approved COVID-19 vaccine. COVAX, co-led by the Coalition for Epidemic Preparedness Innovations, GAVI and the WHO, is the only global initiative that cooperates with governments and partners with vaccine manufacturers to ensure that all developed and developing countries have access to the COVID-19 vaccine. ${ }^{82,83}$

The first three waves of COVID-19 have ended in many countries, while the fourth wave might be about to begin, even stronger, in some settings including Iran. During the first wave, some countries presented better preparedness and implemented more effective policies to control the disease with less casualties than others. The present study highlighted the fundamental role of appropriate policy making, in terms of the type, approach, time, comprehensiveness and manner in reaching the final outcome of the COVID-19 crisis. It is evident that countries that took the threat of pandemic seriously even before the beginning of the crisis, were able to prevent the virus spread by taking timely measures and therefore achieved far better outcomes. More importantly, timely and strong political support, emphasis on conducting more and more diagnostic tests, and contact tracing through the use of novel technologies also influenced the effective performance of more successful countries in response to the pandemic. Adequate resource allocation is necessary but not enough. Delays in emergency response and failure to take the spread of the disease seriously, delayed case identification, inadequate inter-sectoral collaboration, inappropriate surveillance, monitoring \& evaluation system, and lack of coordinated and integrated policies, in addition to weak political support were also the main reasons behind undesirable outcomes.

Over a year into the crisis, 2.6 million global citizens have lost their lives due to COVID-19 pandemic. The crisis is hitting many countries, including the European countries that had already begun to lift some restriction and are now placing more limitations again. Iran just passed its worst experience since the beginning of the pandemic and is expecting another devastating wave. The interesting observations in the Southern hemisphere, which finished the winter season with considerably lower cases of seasonal influenza, might remind us that until global and equitable distribution of the reliable vaccines, there is no other way to control COVID-19 spread than simple measures including mask wearing, social distancing and washing hands frequently. Applying experiences and health policy learning is essential for more efficient performance during this difficult time. We are all together in this and need to learn and act together until we defeat the crisis.

\section{Authors' Contribution}

AT conceived and supervised the study and edited the manuscript. AR (the first author) collected data, initially analyzed and interpreted data, and drafted the manuscript. $\mathrm{HH}$ contributed in data gathering, analyzing and drafting manuscript. AR (the fourth author), ZR, $S R$ contributed in data gathering and drafting manuscript. $A O$, AAS provided experts' opinion, helped in data interpretation and commented on intellectual development of manuscript. All authors read and approved the final draft. AT is guarantor.

\section{Conflict of Interest Disclosures}

We have no conflicts of interest to disclose. 


\section{Ethical Statement}

This study is approved by the ethics committee of Tehran University of Medical Sciences on March 16, 2020 (Approval ID: IR.TUMS. VCR.REC.1398.1064).

\section{Acknowledgements}

We would like to express our appreciation to the experts who enriched the article with their valuable comments.

\section{Supplementary Materials}

Supplementary file 1 contains Tables S1-S4.

\section{References}

1. Kocak Tufan Z, Kayaaslan B. Crushing the curve, the role of national and international institutions and policy makers in COVID-19 pandemic. Turk J Med Sci. 2020;50(SI-1):495-508. doi: 10.3906/sag-2004-167.

2. Habibzadeh P, Stoneman EK. The Novel Coronavirus: A Bird's Eye View. Int J Occup Environ Med. 2020;11(2):65-71. doi: 10.15171/ijoem.2020.1921.

3. Shah SGS, Farrow A. A commentary on "World Health Organization declares global emergency: A review of the 2019 novel Coronavirus (COVID-19)". Int J Surg. 2020;76:128-9. doi: 10.1016/j.ijsu.2020.03.001.

4. Kickbusch I, Leung GM, Bhutta ZA, Matsoso MP, Ihekweazu C, Abbasi K. Covid-19: how a virus is turning the world upside down. BMJ. 2020;369:m1336. doi: 10.1136/bmj.m1336.

5. Takian A, Aarabi M, Haghighi H. The role of universal health coverage in overcoming the covid-19 pandemic. The BMJ Opinion [Internet]. 2020 Apr 20 [cited 2020 May 28]. Available from: https://blogs.bmj.com/bmj/2020/04/20/therole-of-universal-health-coverage-in-overcoming-the-covid19-pandemic/.

6. World Health Organization. 2019 Novel Coronavirus (2019-nCoV): strategic preparedness and response plan WHO; 2020 [updated 2020 Feb 3; cited 2020 Mar 4]. Available from: https://www.who.int/docs/default-source/coronaviruse/srp04022020.pdf.

7. Purcell LN, Charles AG. An Invited Commentary on "World Health Organization declares global emergency: A review of the 2019 novel Coronavirus (COVID-19)": Emergency or new reality? Int J Surg. 2020;76:111. doi: 10.1016/j. ijsu.2020.03.002.

8. World Health Organization. WHO Coronavirus Disease (COVID-19) Dashboard WHO; 2020 [updated 2020 May 28; cited 2020 April 10]. Available from: https://covid19.who.int/.

9. Khanna RC, Cicinelli MV, Gilbert SS, Honavar SG, Murthy GSV. COVID-19 pandemic: Lessons learned and future directions. Indian J Ophthalmol. 2020;68(5):703-10. doi: 10.4103/ijo.IJO_843_20.

10. Legido-Quigley $H$, Asgari $N$, Teo YY, Leung GM, Oshitani H, Fukuda K, et al. Are high-performing health systems resilient against the COVID-19 epidemic? Lancet. 2020;395(10227):848-50. doi: 10.1016/s01406736(20)30551-1.

11. Raoofi A, Takian A, Akbari Sari A, Olyaeemanesh A, Haghighi H, Aarabi M. COVID-19 Pandemic and Comparative Health Policy Learning in Iran. Arch Iran Med. 2020;23(4):220-34. doi: 10.34172/aim.2020.02.

12. Jernigan DB. Update: Public Health Response to the Coronavirus Disease 2019 Outbreak - United States, February 24, 2020. MMWR Morb Mortal Wkly Rep. 2020;69(8):216-9. doi: 10.15585/mmwr.mm6908e1.

13. Legido-Quigley H, Mateos-García JT, Campos VR, GeaSánchez M, Muntaner C, McKee M. The resilience of the Spanish health system against the COVID-19 pandemic. Lancet Public Health. 2020;5(5):e251-e2. doi: 10.1016/ s2468-2667(20)30060-8.
14. Doshmangir L, Bazyar M, Majdzadeh R, Takian A. So near, so far: four decades of health policy reforms in Iran, achievements and challenges. Arch Iran Med. 2019;22(10):592-605.

15. World Health Organization. Everybody's business-strengthening health systems to improve health outcomes: WHO's framework for action. Geneva, Switzerland: World Health Organization; 2007. Available from: https://apps.who. int/iris/bitstream/handle/10665/43918/9789241596077_eng. pdf.

16. World Health Organization. Monitoring the building blocks of health systems: a handbook of indicators and their measurement strategies. Geneva, Switzerland: World Health Organization; 2010. 110 p. Available from: https://www. who.int/healthinfo/systems/WHO_MBHSS_2010_full_web. pdf? ua $=1$.

17. Roser M, Ritchie H, Ortiz-Ospina E, Hasell J. Coronavirus Pandemic (COVID-19). Total confirmed COVID-19 cases per million people. Oxford: Our World in Data; 2020 [updated 2020 Sep 1; cited 2020 Sep 1]. Available from: https:// ourworldindata.org/grapher/total-confirmed-cases-of-covid19-per-million-people?year=2020-04-15.

18. Roser M, Ritchie H, Ortiz-Ospina E, Hasell J. Coronavirus Pandemic (COVID-19). Daily COVID-19 tests per thousand people. Oxford: Our World in Data; 2020 [updated 2020 Aug 31; cited 2020 Aug 31]. Available from: https://ourworldindata. org/coronavirus/country/united-kingdom?country $=\mathrm{GBR} \sim \mathrm{CH}$ $\mathrm{N} \sim \mathrm{DEU} \sim$ IRN $\sim$ ITA $\sim$ JPN SGP KOR ESP USA.

19. Institute for Health Metrics \& Evaluation. COVID-19 Projections. Washington, DC: IHME; 2020 [updated 2020 Aug 28; cited 2020 Sep 1]. Available from: https://covid19. healthdata.org/.

20. Villela DAM. The value of mitigating epidemic peaks of COVID-19 for more effective public health responses. Rev Soc Bras Med Trop. 2020;53:e20200135. doi: 10.1590/00378682-0135-2020.

21. World Health Organization. Statement on the second meeting of the International Health Regulations (2005) Emergency Committee regarding the outbreak of novel coronavirus (2019-nCoV) Geneva, Switzerland: WHO; 2020 [updated 2020 Jan 30; cited 2020 Jan 30]. Available from: https:// www.who.int/news-room/detail/30-01-2020-statement-onthe-second-meeting-of-the-international-health-regulations(2005)-emergency-committee-regarding-the-outbreak-of-novel-coronavirus-(2019-ncov).

22. World Health Organization. Country \& Technical Guidance Coronavirus disease (COVID-19) Geneva, Switzerland: WHO; 2020 [updated 2020 Apr 28; cited 2020 Mar 25]. Available from: https://www.who.int/emergencies/diseases/novelcoronavirus-2019/technical-guidance.

23. Report of the WHO-China Joint Mission on Coronavirus Disease 2019 (COVID-19). 2020 16-24 February 2020. Report No. Available from: https:/www.who.int/publicationsdetail/report-of-the-who-china-joint-mission-on-coronavirusdisease-2019-(covid-19).

24. Prime Minister of Japan and His Cabinet. The Prime Minister in Action. Novel Coronavirus Response Headquarters. Japan: Prime Minister of Japan and His Cabinet; 2020 [updated 2020 January 30; cited 2020 July 2]. Available from: https://japan. kantei.go.jp/98_abe/actions/202001/_00034.html.

25. Dudden A, Marks A. South Korea took rapid, intrusive measures against Covid-19 - and they worked. The Guardian [Internet]. 2020 March 20. Available from: https://www. theguardian.com/commentisfree/2020/mar/20/south-korearapid-intrusive-measures-covid-19. Accessed March 20, 2020.

26. Wong JEL, Leo YS, Tan CC. COVID-19 in Singapore-Current Experience: Critical Global Issues That Require Attention and Action. JAMA. 2020;323(13):1243-4. doi: 10.1001/ jama.2020.2467. 
27. Civil Protection Department. Chronology of main steps and legal acts taken by the Italian Government for the containment of the COVID-19 epidemiological emergency. Italy: Civil Protection Department, 2020 Mar 12. Report No. Available from: http://www.protezionecivile. gov.it/documents/20182/1227694/Summary+of+ measures+taken+against+the+spread +of+C-19/c16459ad4e52-4e90-90f3-c6a2b30c17eb

28. Ministry of Health. [Coronavirus SARS-CoV-2 : Chronicle of previous measures] Germany: Federal Ministry of Health; 2020 [updated 2020 May 14; cited 2020 May 17]. Available from: https://www.bundesgesundheitsministerium.de/coronavirus/ chronik-coronavirus.html.

29. Ministry of Interior, Building and Community. Coronavirus: Frequently Asked Questions Germany: Federal Ministry of the Interior, Building and Community; 2020 [updated 2020 May 6; cited 2020 May 28]. Available from: https://www.bmi.bund. de/SharedDocs/faqs/EN/topics/civil-protection/coronavirus/ coronavirus-faqs.html.

30. Romano A. A new investigation reveals Trump ignored experts on Covid-19 for months USA: VOX; 2020 [updated 2020 April 12; cited 2020 July 12]. Available from: https://www. vox.com/2020/4/12/21218305/trump-ignored-coronaviruswarnings.

31. Coronavirus: Resources, Updates, and What You Should Know USA: The White House; 2020 [updated 2020 May 23; cited 2020 May 23]. Available from: https://www.whitehouse.gov/.

32. Ministry of Health and Medical Education. [Corona Documentary]. Tehran: MoHME; 2020. 89 p. Available from: https://behdasht.gov.ir/uploads/1/2020/Apr/21/01_Tak\%20 page.pdf.

33. IFP Editorial Staff. Rouhani to Chair Iran's Taskforce on Combatting Coronavirus Tehran: IFP News; 2020 [updated 2020 Mar 11; cited 2020 Mar 11]. Available from: https:// ifpnews.com/rouhani-to-chair-irans-taskforce-on-combattingcoronavirus.

34. Hyonhee S. South Korea's emergency exercise in December facilitated coronavirus testing, containment United States: World News. Thomson Reuters; 2020 [updated 2020 Mar 30; cited 2020 Mar 30]. Available from: https://www.reuters.com/ article/us-health-coronavirus-southkorea-drills/south-koreasemergency-exercise-in-december-facilitated-coronavirustesting-containment-idUSKBN21HOBQ.

35. Bedingfield W. What the world can learn from South Korea's coronavirus strategy? Wired [Internet]. 2020 March 21 [cited 2020 May 17]. Available from: https://www.wired.co.uk/ article/south-korea-coronavirus. Accessed March 21, 2020.

36. Eun AJ. A Democratic Response to Coronavirus: Lessons From South Korea The Diplomat [Internet]. 2020 March 30 [cited 2020 May 17]. Available from: https://thediplomat. com/2020/03/a-democratic-response-to-coronavirus-lessonsfrom-south-korea/. Accessed March 30, 2021.

37. Tiang J, Ma D, Huang S, Han W. In Depth: Why South Korea is winning the coronavirus battle CHina: Nikkei Asian Review; 2020 [updated 2020 May 17; cited 2020 May 17]. Available from: https://asia.nikkei.com/Spotlight/Caixin/In-Depth-WhySouth-Korea-is-winning-the-coronavirus-battle.

38. Kim J-Y, Choe P-G, Oh Y, Oh K-J, Kim J, Park S-J, et al. The first case of 2019 novel coronavirus pneumonia imported into Korea from Wuhan, China: implication for infection prevention and control measures. J Korean Med Sci. 2020;35(5). doi: 10.3346/jkms.2020.35.e61.

39. Park J-Y, Han M-S, Park K-U, Kim J-Y, Choi E-H. First pediatric case of coronavirus disease 2019 in Korea. J Korean Med Sci. 2020;35(11):e124. doi: 10.3346/jkms.2020.35.e124.

40. Kupferschmidt K, Cohen J. Can China's COVID-19 strategy work elsewhere? Science. 2020;367(6482):1061-2. doi: 10.1126/science.367.6482.1061.
41. Zhang S, Wang Z, Chang R, Wang H, Xu C, Yu X, et al. COVID-19 containment: China provides important lessons for global response. Front Med. 2020 Apr;14(2):215-219. doi: 10.1007/s11684-020-0766-9.

42. Robert Koch Institute. Supplement to the National Pandemic Plan - COVID-19 - novel coronavirus disease Germany: Robert Koch Institute; 2020 [updated 2020 March 5]. Available from: https://www.rki.de/DE/Content/InfAZ/N/Neuartiges_ Coronavirus/Ergaenzung_Pandemieplan_Covid.html.

43. Tondo L. Coronavirus Italy: PM extends lockdown to entire country Palermo, Italy: The Guardian; 2020 [updated 2020 March 10; cited 2020 July 2]. Available from: https://www. theguardian.com/world/2020/mar/09/coronavirus-italyprime-minister-country-lockdown.

44. Di Donato V, Ruotolo N, Smith-Spark L. Italy calls in military to enforce coronavirus lockdown as 627 people die in 24 hours 2020 [updated 2020 Mar 20; cited 2020 May 9]. Available from: https://edition.cnn.com/2020/03/20/europe/ italy-military-coronavirus-intl/index.html.

45. How did Britain get its coronavirus response so wrong? The UK: Guardian News \& Media; 2020 [updated 2020 Apr 19]. Available from: https://www.theguardian.com/world/2020/ apr/18/how-did-britain-get-its-response-to-coronavirus-sowrong.

46. Helm T, Graham-Harrison E, McKie R. How did Britain get its coronavirus response so wrong? London, United Kingdom: The Guardian; 2020 [updated 2020 April 19; cited 2020 July 2]. Available from: https://www.theguardian.com/world/2020/ apr/18/how-did-britain-get-its-response-to-coronavirus-sowrong\#top.

47. Presidential Information Center. [Important decisions of the National COVID-19 Committee on the time and form of businesses, offices, schools and higher education institutions' activities] Tehran: Presidential Information Center; 2020 [updated 2020 Apr 5; cited 2020 Apr 5]. Available from: http:// president.ir/fa/ 114569 .

48. Ministry of Health and Medical Education. [Implementation of the second step in combating COVID-19 and social distance] Tehran: MoHME; 2020 [updated 2020 May 18; cited 2020 May 18]. Available from: https://cutt.ly/cyKQ5O5.

49. Lee VJ, Chiew CJ, Khong WX. Interrupting transmission of COVID-19: lessons from containment efforts in Singapore. J Travel Med. 2020;27(3):taaa039. doi: 10.1093/jtm/taaa039.

50. Moss P, Barlow G, Easom N, Lillie P, Samson A. Lessons for managing high-consequence infections from first COVID-19 cases in the UK. Lancet. 2020;395(10227):e46.

51. Sorbello M, El-Boghdadly K, Di Giacinto I, Cataldo R, Esposito C, Falcetta $\mathrm{S}$, et al. The Italian coronavirus disease 2019 outbreak: recommendations from clinical practice. Anaesthesia. 2020;75(6):724-732. doi: 10.1111/anae.15049.

52. Vidyarthi AR, Bagdasarian N, Esmaili AM, Archuleta S, Monash B, Sehgal NL, et al. Understanding the Singapore COVID-19 Experience: Implications for Hospital Medicine. J Hosp Med. 2020;15(5):281-3. doi: 10.12788/jhm.3436.

53. Normile D. Coronavirus cases have dropped sharply in South Korea. What's the secret to its success? 2020 [updated 2020 May 9]. Available from: https://www.sciencemag.org/ news/2020/03/coronavirus-cases-have-dropped-sharplysouth-korea-whats-secret-its-success \#.

54. Coronavirus Disease-19, Republic of Korea. COVID-19 Response. Early detection and containment. Republic of Korea: Ministry of Health and Welfare; 2020 [updated 2020 May 15; cited 2020 Feb 25]. Available from: http:// ncov.mohw.go.kr/en/baroView.do?brdld=11\&brdGubun $=111 \&$ dataGubun $=\&$ ncvContSeq $=\&$ contSeq $=\&$ board_id $=$.

55. Stafford N. Covid-19: Why Germany's case fatality rate seems so low. BMJ. 2020;369:m1395. doi: 10.1136/bmj.m1395.

56. Konrad R, Eberle U, Dangel A, Treis B, Berger A, Bengs K, et 
al. Rapid establishment of laboratory diagnostics for the novel coronavirus SARS-CoV-2 in Bavaria, Germany, February 2020. Eurosurveillance. 2020;25(9):2000173. doi: 10.2807/15607917.ES.2020.25.9.2000173.

57. Mahase E. Coronavirus: NHS staff get power to keep patients in isolation as UK declares "serious threat". BMJ. 2020;368:m550. doi: 10.1136/bmj.m550.

58. MacAskill A. UK defends coronavirus response after Reuters investigation. UK: Reuters; 2020 [updated 2020 Apr 9; cited 2020 Apr 9]. Available from: https://uk.reuters.com/article/ukhealth-coronavirus-britain-modelling-idUKKCN21R2UF.

59. Woodcock A. Coronavirus testing still below daily target despite government claim milestone passed. UK: Independent; 2020 [updated 2020 Mar 30; cited 2020 Mar 30]. Available from: https://www.independent.co.uk/news/uk/politics/coronavirustesting-uk-daily-target-nhs-cases-latest-a9434496.html.

60. Mashregh. [What are the lawful prices for corona testing in laboratories?] Tehran: Mashregh; 2020 [updated 2020 Aug 12; cited 2020 Aug 12]. Available from: https://www.mshrgh. $\mathrm{ir} / 1104828$.

61. Doshmangir L, Mahbub-Ahari A, Qolipour K, Azami-Aghdash S, Kalankesh L, Doshmangir P, et al. [East Asia's Strategies for Effective Response to COVID-19: Lessons Learned for Iran]. Management Strategies in Health System. 2020;4(4):370-3.

62. Chatterjee S, Leng C, Zhang Z. China pushes for cheaper health insurance products to battle virus: sources United States: World News. Thomson Reuters; 2020 [updated 2020 May 8; cited 2020 Feb 13]. Available from: https://www. reuters.com/article/us-china-health-insurance/china-pushesfor-cheaper-health-insurance-products-to-battle-virussources-idUSKBN2070R9.

63. Pandemic Response Accountability Committee. Pandemic Oversight. USA: PRAC; 2020 [updated 2020 Sep; cited 2020 Sep 13]. Available from: https://www.pandemicoversight.gov/ track-the-money/funding-overview.

64. Thomson S, Evetovits T. Strengthening the health financing response to COVID-19 in Europe. Barcelona: World Health Organization Regional Office for Europe; 2020. Available from: URL: http://www.euro.who.int/_data/assets/pdf_ file/0003/439617/COVID-19-health-financing-responseEurope.pdf?ua=1.

65. Tasnim News Agency. [The Iranian supreme leader agrees to withdraw 1 billion euros from the National Development Fund] Tehran: Tasnim News Agency; 2020 [updated $2020 \mathrm{Apr}$ 4; cited 2020 Apr 4]. Available from: https://sptnkne.ws/BXg8.

66. Behzadifar M, Ghanbari MK, Bakhtiari A, Behzadifar M, Bragazzi NL. Ensuring adequate health financing to prevent and control the COVID-19 in Iran. International Journal for Equity in Health. 2020;19(1):61. doi: 10.1186/s12939-02001181-9.

67. Russell P. New Coronavirus: UK Public Health Campaign Launched UK: Medscape; 2020 [updated 2020 March 1; cited 20203 February]. Available from: https://www.medscape. com/viewarticle/924664.

68. Lazzerini M, Putoto G. COVID-19 in Italy: momentous decisions and many uncertainties. The Lancet Global health. 2020. doi: 10.1016/S2214-109X(20)30110-8.

69. Ministry of Health and Medical Education. [National Committee on COVID-19 Epidemiology] Tehran: MoHME; 2020 [updated 2020 May 23; cited 2020 Mar 27]. Available from: http://corona.behdasht.gov.ir/.

70. Yoo J-H. Will the Third Wave of Coronavirus Disease 2019
Really Come in Korea? Journal of Korean Medical Science. 2020;35(10):e110. doi: 10.3346/jkms.2020.35.e110.

71. Lee D, Lee J. Testing on the Move South Korea's rapid response to the COVID-19 pandemic. Transp Res Interdiscip Perspect. 2020;5: 100111. doi: 10.1016/j.trip.2020.100111.

72. Ng Y, Li Z, Chua Y-X, Chaw W-L, Zhao Z, Er B, et al. Evaluation of the effectiveness of surveillance and containment measures for the first 100 patients with COVID-19 in Singapore -January 2-February 29, 2020. MMWR Morb Mortal Wkly Rep. 2020 Mar 20;69(11):307-311. doi: 10.15585/mmwr. mm6911e1.

73. National Health Commission of the People's Republic of China. Diagnosis and Treatment Protocol for COVID-19 (Trial Version 7) China: National Health Commission of the PRC; 2020 [updated 2020 Mar 29; cited 2020 Mar 29]. Available from: http://en.nhc.gov.cn/2020-03/29/C_78469.htm.

74. Takian A, Raoofi A, Kazempour-Ardebili S. COVID-19 battle during the toughest sanctions against Iran. Lancet. 2020;395(10229):1035-6. doi: 10.1016/s01406736(20)30668-1.

75. IRNA. [Iran became self-sufficient in the production of corona detection kits] Tehran: IRNA; 2020 [updated 2020 April 1; cited 2020 May 18]. Available from: https://www.irna.ir/ news/83735237/.

76. Tehran Times. Iran among top five producers of COVID-19 rapid antigen-detection kits. Tehran: Tehran Times; 2020 [updated 2020 Nov 17; cited 2020 Feb 16]. Available from: https://www.tehrantimes.com/news/454771/Iran-among-topfive-producers-of-COVID-19-rapid-antigen-detection.

77. Ministry of Health and Medical Education. [The production of three-layer masks in the country increased from 150,000 to 3 million a day] Tehran: MoHME; 2020 [updated 2020 Apr 19; cited 2020 Mar 18]. Available from: https://cutt.ly/ZyRm8er.

78. WHO Emergencies Coronavirus Press Conference [press release]. World Health Organization, 2020 Feb 252020.

79. UK Research and Innovation. COVID-19 vaccine \& therapy research boosted by six new projects in rapid response UKRI; 2020 [updated 2020 Mar 23; cited 2020 Mar 23]. Available from: https://www.ukri.org/news/covid-19-vaccine-therapyresearch-boosted-by-six-new-projects-in-rapid-response/.

80. Gottlieb S. America Needs to Win the Coronavirus Vaccine Race. New York, NY: The Wall Street Journal; 2020 [updated 2020 Apr 26; cited 2020 Sep 6]. Available from: https://www. wsj.com/articles/america-needs-to-win-the-coronavirusvaccine-race-11587924258.

81. World Health Organization. Draft landscape of COVID-19 candidate vaccines WHO; 2020 [updated 2020 Nov 12; cited 2020 Sep 3]. Available from: https://www.who.int/ publications/m/item/draft-landscape-of-covid-19-candidatevaccines.

82. World Health Organization. 172 countries and multiple candidate vaccines engaged in COVID-19 vaccine Global Access Facility WHO; 2020 [updated 2020 Aug 24; cited 2020 Aug 24]. Available from: https://www.who.int/newsroom/detail/24-08-2020-172-countries-and-multiple-candidatevaccines-engaged-in-covid-19-vaccine-global-access-facility.

83. GAVI, the Vaccine Alliance. Up to 100 million COVID-19 vaccine doses to be made available for low- and middleincome countries as early as $2021 \mathrm{WHO} ; 2020$ [updated 2020 Aug 7; cited 2020 Aug 7]. Available from: https://www.gavi. org/news/media-room/100-million-covid-19-vaccine-dosesavailable-low-and-middle-income-countries-2021. 